\title{
Conversion of $\alpha$-linolenic acid to longer-chain polyunsaturated fatty acids in human adults
}

\author{
Graham C. BuRdGE*, Philip C. CALDER \\ Institute of Human Nutrition, University of Southampton, Southampton, UK
}

(Received 21 February 2005; accepted 7 April 2005)

\begin{abstract}
The principal biological role of $\alpha$-linolenic acid ( $\alpha$ LNA; $18: 3 n-3)$ appears to be as a precursor for the synthesis of longer chain n-3 polyunsaturated fatty acids (PUFA). Increasing $\alpha$ LNA intake for a period of weeks to months results in an increase in the proportion of eicosapentaenoic acid (EPA; 20:5n-3) in plasma lipids, in erythrocytes, leukocytes, platelets and in breast milk but there is no increase in docosahexaenoic acid (DHA; 22:6n-3), which may even decline in some pools at high $\alpha$ LNA intakes. Stable isotope tracer studies indicate that conversion of $\alpha$ LNA to EPA occurs but is limited in men and that further transformation to DHA is very low. The fractional conversion of $\alpha$ LNA to the longer chain n-3 PUFA is greater in women which may be due to a regulatory effect of oestrogen. A lower proportion of $\alpha \mathrm{LNA}$ is used for $\beta$-oxidation in women compared with men. Overall, $\alpha$ LNA appears to be a limited source of longer chain n-3 PUFA in humans. Thus, adequate intakes of preformed long chain n-3 PUFA, in particular DHA, may be important for maintaining optimal tissue function. Capacity to up-regulate $\alpha$ LNA conversion in women may be important for meeting the demands of the fetus and neonate for DHA.
\end{abstract}

n-3 polyunsaturated fatty acids / humans / $\alpha$-linolenic acid / metabolism

\begin{abstract}
Abbreviations: $\alpha$ LNA: $\alpha$-linolenic acid; CE: cholesteryl ester; DHA: docosahexaenoic acid; DPAn-3: docosapentaenoic acid; $\mathrm{EE}_{2:}$ 17 $\alpha$-ethynyloestradiol; EPA: eicosapentaenoic acid; MUFA: monounsaturated fatty acid; NEFA: non-esterified fatty acid; PC: phosphatidylcholine; PL: phospholipid; PUFA: polyunsaturated fatty acid; SFA: saturated fatty acid; TAG: triacylglycerol.
\end{abstract}

\section{INTRODUCTION}

$\alpha$-Linolenic acid (18:3n-3, $\alpha$ LNA) is an essential fatty acid in the diet of humans and is the principal n-3 polyunsaturated fatty acid (PUFA) in the western diet. The major dietary sources of $\alpha$ LNA are green leaves, and oils used on cooking such as rapeseed oil and soybean oil where it accounts for up to $10 \%$ of total fatty acids. Some seeds (e.g., flaxseed (also known as linseed)) and nuts (e.g., walnut) are particularly rich in $\alpha$ LNA, as are the oils extracted from those seeds and nuts. Typical consumption of $\alpha$ LNA in

\footnotetext{
* Corresponding author: G.C.Burdge@ soton.ac.uk
} 
Table I. Consumption of linoleic and $\alpha$-linolenic acids among adults in some European countries, and in Australia and North America.

\begin{tabular}{|c|c|c|c|c|c|c|}
\hline & \multicolumn{4}{|c|}{ Fatty acid intake $\left(\mathrm{g} \cdot\right.$ day $\left.^{-1}\right)$} & & \\
\hline & \multicolumn{2}{|c|}{ Linoleic acid } & \multicolumn{2}{|c|}{$\alpha$-Linolenic acid } & \multicolumn{2}{|c|}{ LA: $\alpha$ LNA ratio } \\
\hline & Men & Women & Men & Women & Men & Women \\
\hline Belgium & 16.6 & 12.8 & 1.7 & 1.4 & 9.8 & 9.1 \\
\hline Denmark & 12.0 & 9.0 & 2.2 & 2.1 & 5.5 & 4.3 \\
\hline France & 8.3 & 6.8 & 0.6 & 0.5 & 13.8 & 13.6 \\
\hline France ${ }^{c}$ & 10.6 & 8.1 & 0.9 & 0.7 & 11.8 & 11.6 \\
\hline Germany & 9.3 & 8.0 & 0.9 & 0.7 & 10.3 & 11.4 \\
\hline Netherlands & 19.0 & 13.2 & 1.7 & 1.2 & 28.8 & 11.0 \\
\hline Italy & \multicolumn{2}{|c|}{14.5} & \multicolumn{2}{|c|}{0.8} & \multicolumn{2}{|c|}{18.1} \\
\hline Spain $^{\mathrm{a}}$ & \multicolumn{2}{|c|}{21.6} & \multicolumn{2}{|c|}{0.8} & \multicolumn{2}{|c|}{27.0} \\
\hline $\mathrm{UK}^{\mathrm{a}}$ & \multicolumn{2}{|c|}{14.4} & \multicolumn{2}{|c|}{1.4} & \multicolumn{2}{|c|}{10.3} \\
\hline Australia $^{\mathrm{a}}$ & \multicolumn{2}{|c|}{9.9} & \multicolumn{2}{|c|}{1.2} & \multicolumn{2}{|c|}{8.3} \\
\hline USA & 16.0 & 11.0 & 2.0 & 1.0 & 8.0 & 11.0 \\
\hline Canada & & $11.2^{\mathrm{b}}$ & & $1.6^{\mathrm{b}}$ & & $7.0^{\mathrm{b}}$ \\
\hline
\end{tabular}

a Separate data are not available for men and women.

b Pregnant women. Data for UK from [1]; data for Australia from [3]; data for USA from [4]; data for Canada from [5].

${ }^{c}$ Data for France from [6], other data from [2].

Europe, Australia and North America ranges between 0.6 to $1.7 \mathrm{~g}$ per day in men and 0.5 to $1.4 \mathrm{~g}$ per day in women [1-5] (Tab. I). This is typically about 10 -fold lower than consumption of the n- 6 essential fatty acid linoleic acid (18:2n-6) [1-6] (Tab. I). However, even among fairly similar westernised populations, the relative intakes of these fatty acids differ dramatically (Tab. I).

$\alpha$ LNA can be converted to longer-chain n-3 PUFA such as eicosapentaenoic acid (EPA; 20:5n-5) and docosahexaenoic acid (DHA; 22:6n-3) by the pathway shown in Figure 1. Whether the essentiality of $\alpha$ LNA in the diet primarily reflects the activity of $\alpha$ LNA itself or of longer-chain PUFA synthesised from $\alpha$ LNA is a matter for debate [7]. The concentration of $\alpha$ LNA in phospholipids in plasma, cells and tissues is typically less than $0.5 \%$ of total fatty acids. Thus, the $\alpha$ LNA content of these pools is likely to exert a fairly limited influence on biological function. In the United Kingdom dietary intakes of EPA and DHA are approximately 25 - and 15 -fold lower, respectively, than those of $\alpha$ LNA [1] and similar differences are seen in other countries [3-6]. However, the concentrations of these PUFA in plasma, cell and tissue phospholipids are greater than those of $\alpha$ LNA. This apparent mismatch between dietary intakes and concentrations in plasma, cell and tissue lipids further suggests that the primary biological role of $\alpha$ LNA is as a substrate for EPA and DHA synthesis. However, it is possible that the low concentration of $\alpha$ LNA in plasma, cell and tissues may also reflect negative selection in the incorporation of $\alpha$ LNA into plasma and membrane lipid pools.

The effect of $\alpha$ LNA deficiency on neurological function supports the role of $\alpha$ LNA as a precursor to longer chain $n-3$ PUFA which are critical in the function of the central nervous system [8]. The DHA content of neural membrane phospholipids modulates the activities of several signalling pathways in the brain [6] and is critical for optimal retinal function [9, 10]. Fifty 


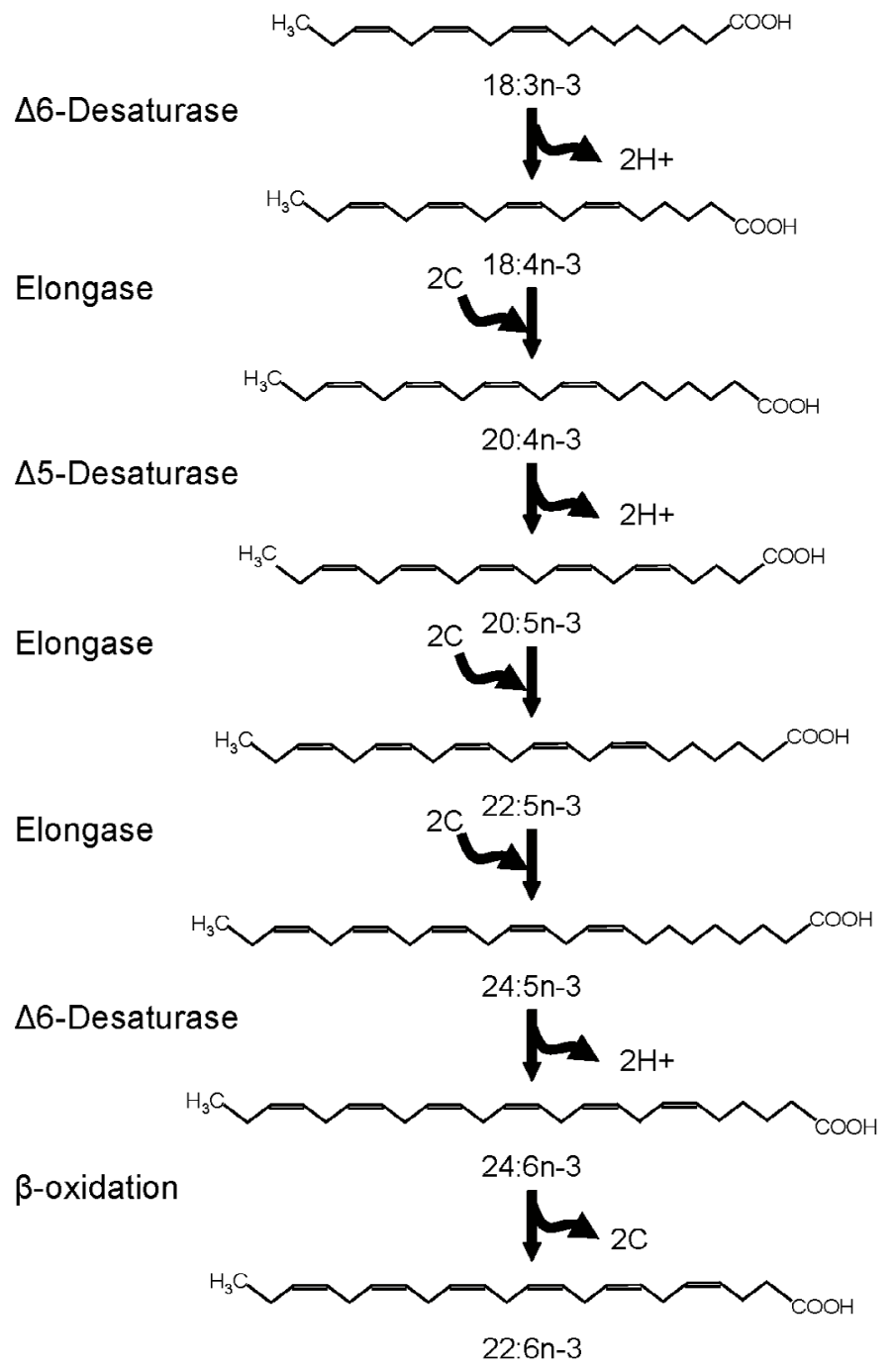

Figure 1. A general pathway for the conversion of $\alpha$-linolenic acid into longer-chain $n-3$ polyunsaturated fatty acids (based on reference [35]).

percent of children and $30 \%$ of adults receiving long-term total parenteral nutrition lacking $\alpha$ LNA exhibited visual dysfunction, which suggests decreased availability of DHA for incorporation into neural membranes [11]. The offspring of monkeys fed an n-3 PUFA deficient diet during preg- nancy show visual impairments [12]. Supplementation of the infant monkeys with $\alpha$ LNA resulted in an increase in the concentration of DHA in neural tissues and an improvement in visual function [13]. This suggests that a deficit in the availability of $\alpha$ LNA for conversion to, in particular, 
DHA was the principal mechanism underlying the deficiency symptoms.

Increased consumption of oily fish or taking fish oil supplements has been shown to increase plasma, cell and tissue EPA and DHA concentrations which is associated with benefits to health, particularly in relation to cardiovascular and inflammatory diseases [14-17]. However, the efficacy of recommendations to increase EPA and DHA intakes [14, 15, 18-20] may be limited by patterns of food choice and availability of fish stocks to sustain the supply of oily fish or fish oil. If $\alpha$ LNA can substitute for long chain n-3 PUFA then recommendations to increase its intake could be made. In order to support these, the ability of $\alpha$ LNA to be converted to longer-chain n-3 PUFA and so to increase plasma, cell and tissue pools with EPA and DHA needs to be determined. Furthermore differences among populations or population subgroups and the reasons for these need to be identified. The purpose of this review is to discuss the extent to which conversion of $\alpha$ LNA to longer chain n-3 PUFA occurs in adult humans and how this process may differ between groups of individuals. $\alpha$ LNA metabolism in human infants will not be considered as these represent a distinct group with specific demands for long chain PUFA which differ in magnitude from adults.

\section{BIOAVAILABILITY AND HANDLING OF $\alpha$-LINOLENIC ACID FROM THE DIET}

The bioavailability of dietary $\alpha$ LNA for conversion to longer-chain PUFA is determined by the efficiency of absorption across the gastrointestinal tract, uptake and partitioning towards $\beta$-oxidation, and incorporation into structural and storage pools.

\subsection{Absorption of $\alpha$-linolenic acid}

There is very little information regarding the absorption of $\alpha$ LNA by the human gut.
Measurement of the concentrations of deuterated fatty acids in chylomicron triacylglycerol (TAG) following ingestion of deuterated $\alpha$ LNA as synthetic TAG showed that the absorption and secretion of oleic acid (18:1n-9), linoleic and $\alpha$ LNA were similar [21]. Although this does not specifically measure absorption across the gut, it does indicate that the overall bioavailability of $\alpha$ LNA is similar to that of other unsaturated fatty acids. Measurement of the cumulative concentration of labeled $\alpha$ LNA in stool collected over 5 days following ingestion of $750 \mathrm{mg}\left[U_{-}{ }^{13} \mathrm{C}\right] \alpha \mathrm{LNA}$ showed that greater than $96 \%$ of the administered dose was absorbed (G.C. Burdge, unpublished observation). Comparable levels of $\alpha$ LNA uptake have also been reported in patients with ileostomies who were fed $100 \mathrm{~g}$ linseed oil [22]. These findings suggest that absorption of $\alpha$ LNA across the gut and its secretion into the bloodstream are efficient.

\subsection{Assimilation of $\alpha$-linolenic acid into adipose tissue}

Adipose tissue accounts for approximately $15 \%$ of body mass in males and $23 \%$ of body mass in females. Thus incorporation of $\alpha \mathrm{LNA}$ into this storage pool represents a potentially important route of disposal of dietary $\alpha$ LNA and a reserve pool which is available for mobilisation during periods of increased demands. $\alpha$ LNA accounts for about $0.7 \%$ of total fatty acid neutral lipids in adipose tissue in men and women, while DHA concentration is approximately $0.1 \%$ and EPA is practically undetectable [23, 24]. Thus, it can be calculated that, in a $75 \mathrm{~kg}$ man with a fat mass of $15 \%$, the whole body $\alpha$ LNA reserve in adipose tissue would be approximately $79 \mathrm{~g}$ (roughly equivalent to typical intake over 53 days). Likewise, in a $65 \mathrm{~kg}$ woman with a fat mass of $23 \%$, the whole body $\alpha$ LNA reserve in adipose tissue would be approximately $105 \mathrm{~g}$ (roughly equivalent to typical intake over 70 days).

Following ingestion of a meal there is a metabolic drive to store fatty acids which is 
facilitated by the insulin-dependent increase in lipoprotein lipase activity in adipose tissue. In the fasting state, plasma non-esterified fatty acids (NEFA) are derived primarily from release of adipose tissue TAG stores by the action of hormone-sensitive lipase. The exchange of $\alpha$ LNA between the blood and adipose tissue compartments has not been characterised in humans in vivo. However, when men consumed $\left[U_{-}{ }^{13} \mathrm{C}\right] \alpha \mathrm{LNA}$, labelled $\alpha$ LNA was detected in plasma NEFA pool within two hours and reached a peak at six hours [25]. While a proportion of labeled $\alpha$ LNA detected in the NEFA pool in the early postprandial period probably reflects incomplete entrapment of fatty acids released by hydrolysis of chylomicron TAG [26], at $6 \mathrm{~h}$ after consumption of the meal the presence of labeled $\alpha$ LNA in plasma NEFAs probably reflects mobilisation of recently assimilated fatty acid. The overall effect of rapid release of $\alpha$ LNA into the NEFA pool, together with the $\alpha$ LNA pool associated with chylomicron remnant particles, would tend to facilitate supply of $\alpha$ LNA to the liver.

The concentration of $\left[{ }^{13} \mathrm{C}\right] \alpha \mathrm{LNA}$ in plasma NEFAs was 2-fold greater in women than in men over 21 days [27]. This suggests gender differences in the metabolism of $\alpha$ LNA in storage pools and potentially greater short-term availability of $\alpha \mathrm{LNA}$ for supply to the liver in women.

\subsection{Disposal of $\alpha$-linolenic acid by $\beta$-oxidation}

$\alpha$ LNA is a substrate for $\beta$-oxidation in humans and the proportion of ingested $\left[{ }^{13} \mathrm{C}\right] \alpha \mathrm{LNA}$ used in $\beta$-oxidation has been estimated from the appearance of labeled $\mathrm{CO}_{2}$ in breath. The values reported to date for the amount of labeled $\alpha$ LNA which is used in $\beta$-oxidation probably represent an approximately $30 \%$ underestimate of the actual proportion of ingested $\alpha \mathrm{LNA}$ used in energy production due to trapping of ${ }^{13} \mathrm{CO}_{2}$ in bicarbonate pools [28]. Since the period of collection of $\mathrm{CO}_{2}$ differs between reports from 9 to $48 \mathrm{~h}$ the estimates of partitioning towards $\beta$-oxidation differ from 15 to $33 \%$ $[25,29-31]$. When subjects were studied under comparable conditions, the fractional $\beta$-oxidation of $\alpha$ LNA in women was estimated as $22 \%$ of administered dose compared to $33 \%$ in men $[25,27]$. This may reflect lower muscle mass in women, and the potential overall effect would be to increase availability of $\alpha \mathrm{LNA}$ for conversion to longer chain PUFA in women compared to men. The extent of partitioning of $\alpha$ LNA towards $\beta$-oxidation, when assessed under identical conditions, was almost twice that of palmitic, stearic and oleic acids [29], which may reflect the higher affinity of carnitine palmitoyl trasnsferase- 1 for $\alpha$ LNA [32]. Since $\alpha$ LNA is essential in the human diet, this finding is somewhat counterintuitive and there is currently no explanation for the preferential use of $\alpha$ LNA as an energy source. One study has reported the effect of altering the n-3 PUFA content of the background diet on the proportion of ingested $\left[{ }^{13} \mathrm{C}\right] \alpha \mathrm{LNA}$ recovered as ${ }^{13} \mathrm{CO}_{2}$ on breath [33]. Three groups of men matched for body-mass-index, age and fasting plasma TAG concentrations consumed a standard meal containing $700 \mathrm{mg}\left[U_{-}{ }^{13} \mathrm{C}\right] \alpha \mathrm{LNA}$ and excretion of ${ }^{13} \mathrm{CO}_{2}$ on breath was measured over $24 \mathrm{~h}$. Subjects then consumed either a control diet $(\alpha \mathrm{LNA} 1.7 \mathrm{~g}$ per day, EPA $+\mathrm{DHA}$ $0.4 \mathrm{~g}$ per day), a diet containing an increased amount of $\alpha$ LNA ( $\alpha$ LNA $9.6 \mathrm{~g}$ per day; EPA + DHA $0.4 \mathrm{~g}$ per day) or a diet containing an increased amount of EPA + DHA ( $\alpha$ LNA $1.7 \mathrm{~g}$ per day; EPA + DHA $1.6 \mathrm{~g}$ per day) for 8 weeks. There was no difference in energy intake between groups. The proportion of ingested labeled $\alpha$ LNA recovered as ${ }^{13} \mathrm{CO}_{2}$ on breath was then measured again. There was no significant difference between baseline and the end of the 8 week intervention period in the proportion of labeled $\alpha$ LNA partitioned towards $\beta$-oxidation in the group consuming the control $(33.1 \%$ vs. $38.9 \%)$, increased $\alpha \mathrm{LNA}$ $(36.1 \%$ vs. $34.3 \%)$ or increased EPA + DHA (32.3\% vs. $38.3 \%$ ) diets. This suggests that 
the extent of partitioning of $\alpha$ LNA towards $\beta$-oxidation is relatively stable over short periods of time and that altering the amount of either $\alpha$ LNA or long chain-3 PUFA in the diet does not significantly alter this process.

In addition to conversion to $\mathrm{CO}_{2}$ by the activity of Kreb's cycle, carbon in acetylCoA generated by fatty acid $\beta$-oxidation may be recycled and used in fatty acid synthesis de novo. This process has been suggested to be important as a source of fatty acids in pregnant and fetal monkeys [34] and rats $[35,36]$. However, there is only one report in humans which describes recycling of carbon released by $\beta$-oxidation of $\alpha$ LNA [37]. Men (35 years of age) and women (28 years of age) consumed $700 \mathrm{mg}\left[U_{-}{ }^{13} \mathrm{C}\right] \alpha \mathrm{LNA}$ and the concentrations of labeled saturated (SFA) and monounsaturated (MUFA) fatty acids in plasma were measured over 21 days. Labelled palmitic, stearic, palmitoleic and oleic acids were detected in plasma phosphatidylcholine (PC) and TAG but not other plasma lipid pools in both men and women. The proportion of label was 6-fold greater in plasma PC compared to TAG in men and 25-fold greater in plasma PC than TAG in women. The concentrations of SFA and MUFA in plasma are greater in TAG than PC. Thus these data suggest channeling of SFA and MUFA synthesised by the recycling pathway into phospholipids by the liver in contrast to the molecular partitioning of the bulk of the hepatic SFA and MUFA pools towards TAG.

The total concentration of labeled SFA and MUFA in plasma lipids was $20 \%$ greater in men compared with women. This is in agreement with greater partitioning of $\alpha$ LNA towards $\beta$-oxidation in men compared to women (see earlier). One overall implication of these findings is that the extent of partitioning of $\alpha$ LNA towards $\beta$-oxidation and carbon recycling may be important in the regulation of the availability of $\alpha$ LNA for conversion to longer-chain PUFA.

\section{CONVERSION OF $\alpha$-LINOLENIC ACID TO LONGER-CHAIN POLY- UNSATURATED FATTY ACIDS}

\subsection{The pathway for conversion of $\alpha$-linolenic acid to longer-chain polyunsaturated fatty acids}

A pathway for the conversion of the essential fatty acids LA and $\alpha$ LNA to longer-chain PUFA has been described in rat liver (reviewed in [38]) and is summarized in Figure 1. With the exception of the final reaction which results in the formation of DHA, all reactions occur in the endoplasmic reticulum. Since both $n-6$ and n-3 PUFA are metabolized by the same desaturation/elongation pathway, there exists potential for competition between these two families of fatty acids. The initial conversion of $\alpha$ LNA to $18: 4 n-3$ by the action of $\Delta 6$-desaturase is the rate limiting reaction of the pathway. The affinity of $\Delta 6$ desaturase for $\alpha$ LNA is greater than for LA [38]. However, the typically higher concentration of LA than $\alpha$ LNA in cellular pools results in greater conversion of n-6 PUFA. The introduction of a double bond at the $\Delta 6$ position is followed by the addition of $\mathrm{C}_{2}$ by elongase activity and then by desaturation at the $\Delta 5$ position by $\Delta 5$-desaturase to form EPA. Docosapentaenoic acid (22:5n-3, DPAn-3) is synthesized from EPA by addition of $\mathrm{C}_{2}$. The conversion of DPAn-3 to DHA has been a matter of controversy and $\Delta 4$-desaturase activity has been suggested to be the primary mechanism for DHA synthesis [39]. However, of studies in which subcellular organelles were isolated and then recombined [40] and reports of the action of the specific $\Delta 6$-desaturase inhibitor SC-26196 [41] strongly support the suggestion that synthesis of DHA involves desaturation at the $\Delta 6$-position as follows. DPAn-3 is elongated to $24: 5 n-3$ which is desaturated at the $\Delta 6$-position by the action of $\Delta 6$-desaturase activity to form 24:6n-3. It is unclear whether the same enzyme is responsible for desaturation of $\alpha \mathrm{LNA}$ and $24: 5 n-3$ [42, 43]. 24:6n-3 is translocated 
from the endoplasmic reticulum to the peroxisome where the acyl chain is shorted by $\mathrm{C}_{2}$ by one cycle of the $\beta$-oxidation pathway to form DHA. DHA is then translocated back to the endoplasmic reticulum. Although the precise regulation of the translocation steps and limited $\beta$-oxidation is not known, it is possible that this represents a locus for metabolic regulation that facilitates control of DHA synthesis independently from the preceding steps of the pathway.

\section{2. $\alpha$-Linoleic acid conversion to longer chain n-3 polyunsaturated fatty acids in adult humans}

Current understanding of the extent to which humans can convert $\alpha$ LNA to longer-chain PUFA is based on two types of evidence: the findings of studies reporting the effects of chronic increases in intake of $\alpha$ LNA on concentrations of n-3 PUFA in plasma, cell and tissue lipid pools and shorter term studies in which subjects consume a bolus of $\alpha$ LNA labeled with a stable isotope.

\subsubsection{Effects of chronically increased $\alpha$-linolenic acid consumption}

A number of studies have reported the effects of consuming increased amounts of $\alpha$ LNA, usually via inclusion of oils with a high $\alpha$ LNA content or of products made with those oils (e.g., spreads) in the diet, on the fatty acid composition of plasma or cell lipids (Tabs. II and III). These studies were conducted either in men or in mixed groups of men and women, used intakes of $\alpha$ LNA ranging from less that one to more than $18 \mathrm{~g} \cdot \mathrm{day}^{-1}$ and were of a few weeks to many months duration (Tabs. II and III). These studies consistently demonstrate increased proportions of EPA in both plasma and cell lipids when $\alpha$ LNA intake is increased (Tabs. II and III). Increases in $\alpha$ LNA intake such that total intake exceeds $4.5 \mathrm{~g} \cdot \mathrm{day}^{-1}$ appear to result in enhancements in EPA content of plasma phospholipids of between 33 and $370 \%$ [44-50]. While the relation-

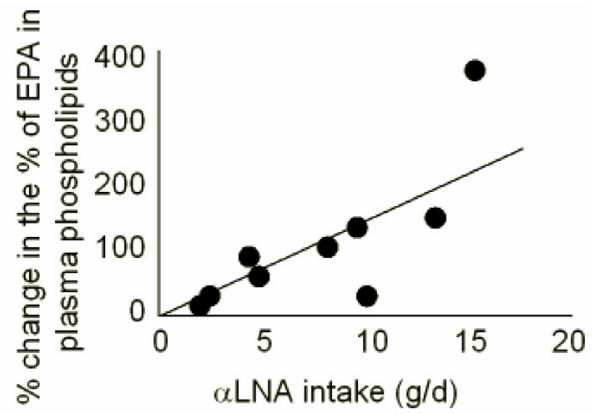

Figure 2. The relationship between $\alpha$-linolenic acid intake and the increase in EPA content of plasma phospholipids. Data for mean change in EPA content are taken from the studies described in Table II.

ship between $\alpha$ LNA intake and EPA incorporation is a significant linear one $(r=$ 0.795; Fig. 2), there is some variation in the response between studies which might reflect differences in age and gender mix of the subjects studied, differences in background diet (e.g., habitual long chain n-3 PUFA intake, linoleic acid intake), differences in the way in which $\alpha$ LNA was provided and differences in analytical procedures used.

Because of competition for metabolism between LA and $\alpha$ LNA, the LA content of the diet may influence conversion of $\alpha$ LNA to longer chain derivatives. If this is so then the EPA content of blood and cell lipids should be greater at a given intake of $\alpha$ LNA if LA intake is decreased. A study by Chan et al. [51] demonstrated that this is the case. Subjects consumed diets providing $7 \mathrm{~g}$ $\alpha L N A \cdot$ day $^{-1}$ for 18 days against a background of either 21 or $50 \mathrm{~g} \mathrm{LA} \cdot \mathrm{day}^{-1}$. The proportion of EPA was higher after the low compared with the high LA background in plasma PC (0.8 vs. $0.3 \%$ of fatty acids), plasma phosphatidylethanolamine (0.9 vs. $0.3 \%$ of fatty acids) and platelet PC ( 0.25 vs. $0.1 \%$ of fatty acids).

Several studies also demonstrate increased proportions of DPAn-3 in plasma and cell lipids when $\alpha$ LNA consumption is increased 


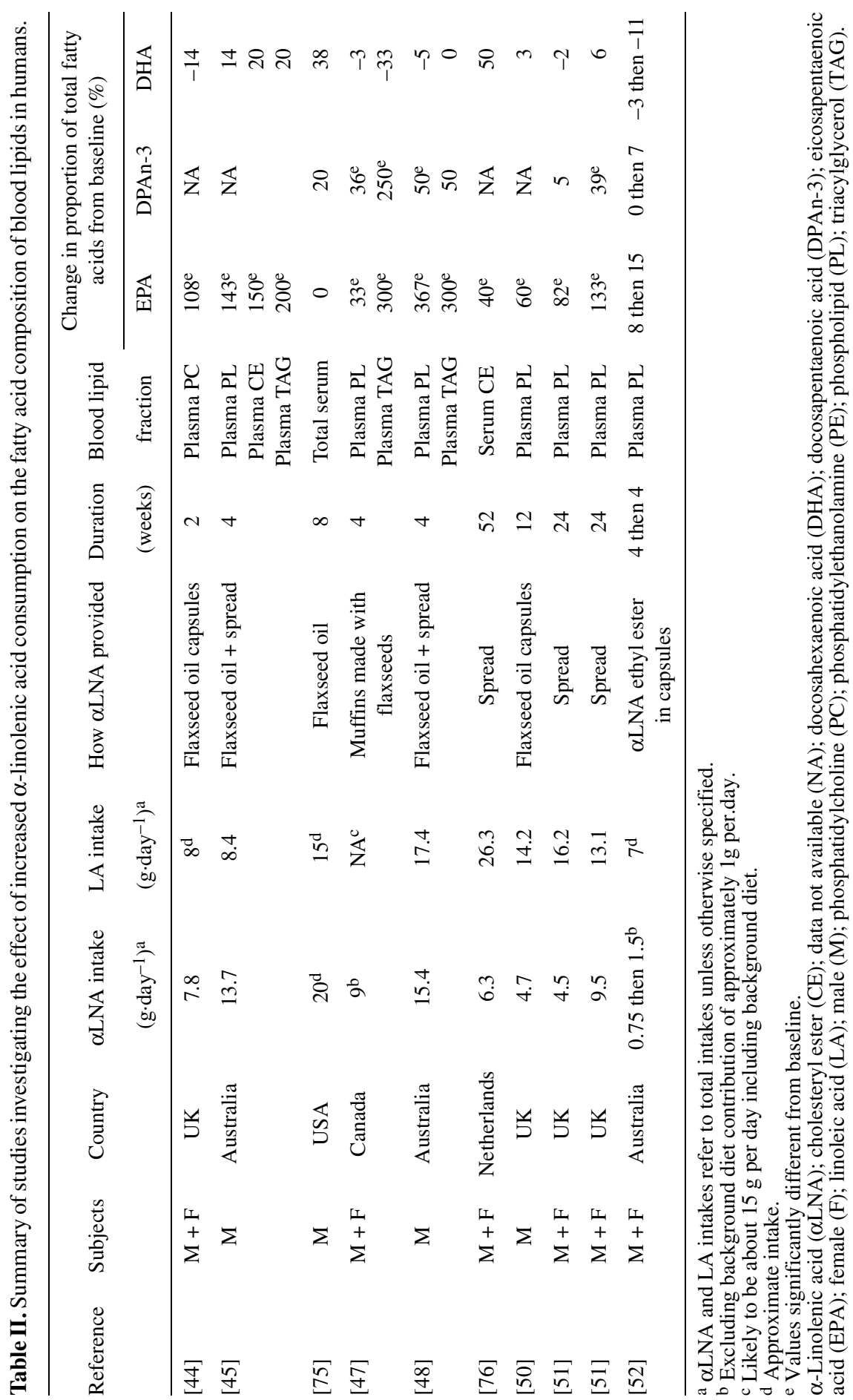




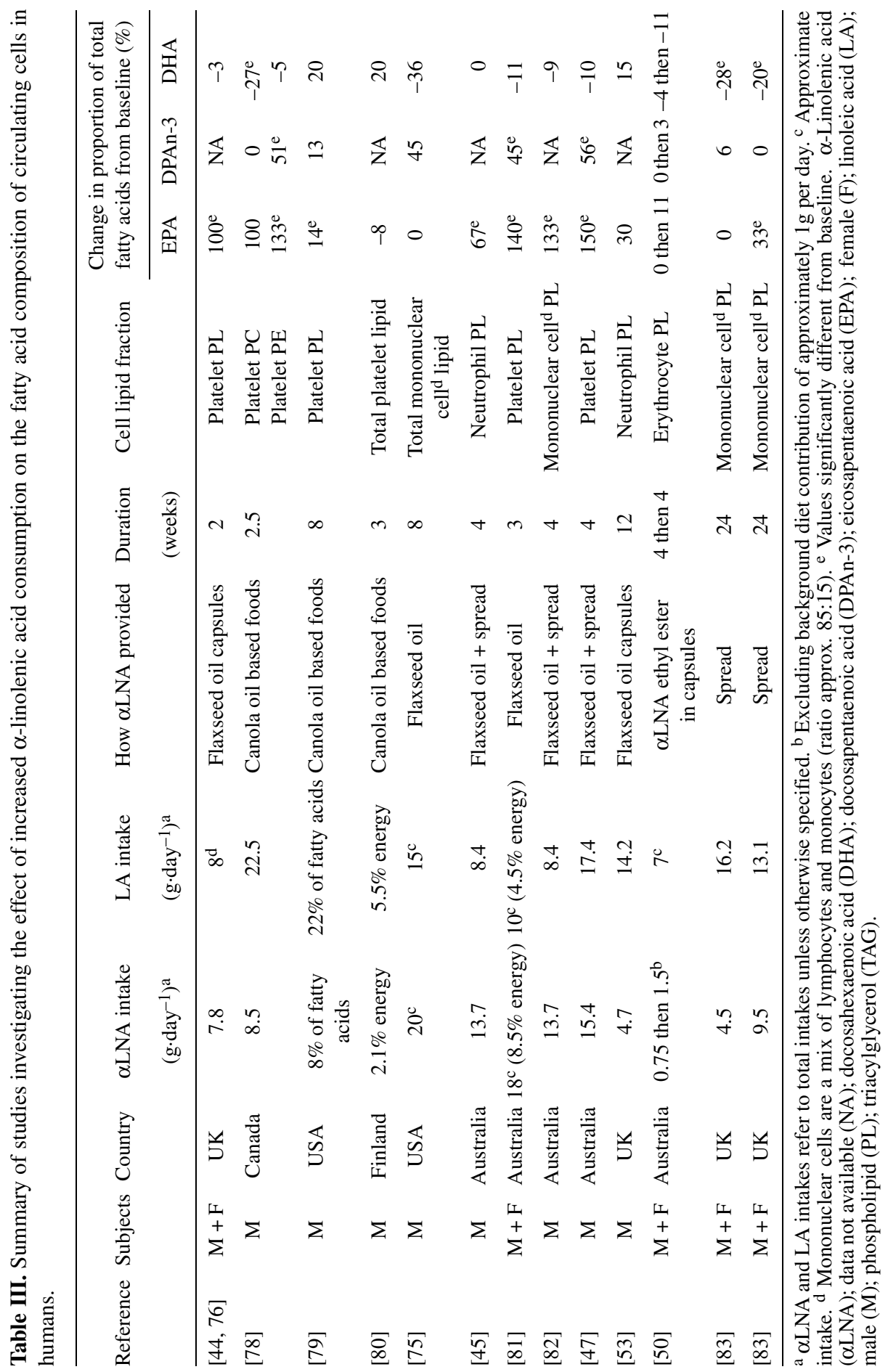


Table IV. Estimated conversion of conversion of $\alpha$ LNA to longer chain polyunsaturated fatty acids based on stable isotope tracer studies.

\begin{tabular}{|c|c|c|c|c|}
\hline \multirow[b]{2}{*}{ Reference } & \multicolumn{4}{|c|}{ Outcome measures } \\
\hline & & EPA & DPA & DHA \\
\hline [19] & $\begin{array}{l}\text { Absolute and relative AUC con- } \\
\text { centrations in total plasma lipids }\end{array}$ & $50 \mu \mathrm{g} \cdot \mathrm{mL}^{-1}(8 \%)$ & $26 \mu \mathrm{g} \cdot \mathrm{mL}^{-1}(4 \%)$ & $25 \mu \mathrm{g} \cdot \mathrm{mL}^{-1}(4 \%)$ \\
\hline [61] & $\begin{array}{l}\text { Peak concentrations in total } \\
\text { plasma lipids }\end{array}$ & $57 \mathrm{ng} \cdot \mathrm{mL}^{-1}$ & ND & $<2 \mathrm{ng} \cdot \mathrm{mL}^{-1}$ \\
\hline [28] & $\begin{array}{l}\text { Peak concentrations adjusted for } \\
\text { estimated total blood volume }\end{array}$ & $120 \mu \mathrm{g}$ & $50 \mu \mathrm{g}$ & $\approx 10 \mu \mathrm{g}$ \\
\hline [23] & $\begin{array}{l}\text { Concentrations in plasma TAG, } \\
\text { NEFA and PC over } 21 \text { days. } \\
\text { Fractional conversion estimated } \\
\text { from time } \times \text { concentration AUC }\end{array}$ & $8 \%$ & $8 \%$ & Not detected \\
\hline
\end{tabular}

Subjects were either men or mixed groups of men and women. Triacylglycerol (TAG), non-esterified fatty acid (NEFA), phosphatidylcholine (PC), cholesteryl ester (CE). ND = not determined.

(Tabs. II and III). The studies also consistently demonstrate that increased consumption of $\alpha$ LNA does not result in increased proportions of DHA in plasma or cell lipids (Tabs. II and III). Indeed many studies report a tendency for DHA to decline when $\alpha$ LNA consumption is markedly increased, although few studies have identified this as a statistically significant effect (Tabs. II and III). Overall, these studies demonstrate that chronically increased consumption of $\alpha$ LNA results in conversion to EPA resulting in increases in EPA concentration in plasma and cell pools, while the extent of conversion to DHA is insufficient to increase the concentration of this fatty acid.

\subsubsection{Estimates $\alpha$-linolenic acid conversion from stable isotope tracer studies}

Development of sophisticated mass spectrometry techniques, in particular gas chromatography combined with either chemical ionisation or isotope ratio mass spectrometry, and the availability of $\alpha$ LNA labelled with stable isotopes which avoid the biological hazards associated with radioisotopes have allowed detailed investigations of the metabolic fate of ingested $\alpha$ LNA in humans. The advantages and limitations of these techniques in humans have been reviewed recently [52]. While there are advantages in terms of safety, there are unresolved issues regarding standardisation of quantification of data (particularly how conversion between fatty acids should be estimated), kinetic modelling, variation between subjects including age and gender, the method of administration of the labelled fatty acid, the duration of the study, the extent to which the background diet is controlled and the use of measurements of labelled fatty acids in blood (including which lipid pool should be measured) as a marker of fatty acid metabolism within tissues [53]. Together these factors have resulted in considerable heterogeneity in the findings of studies of $\alpha$ LNA metabolism in humans using stable isotope tracers [21, 23, 25, 27, 32, 54-57]. This presents a considerable challenge to any attempt to reach a consensus view on $\alpha$ LNA metabolism in man. Nevertheless, at present there are no practical alternatives to these stable isotope tracer techniques to study $\alpha$ LNA metabolism in humans in vivo.

The outcomes of stable isotope tracer studies designed to investigate conversion of $\alpha$ LNA to longer-chain PUFA in humans are summarized in Table IV. Despite the heterogeneity of the study design and the 
mode of expression of results, the consensus of the studies summarised in Table IV is that the proportion of $\alpha$ LNA entering the desaturation/elongation pathway and converted to EPA is low, possibly in the order of $8 \%[21,25]$. The extent of conversion of $\alpha$ LNA to DHA is less clear (Tab. IV). The highest estimated fractional conversion is 4\% [21], while most other studies have reported lower estimates of conversion (less than $0.05 \%$ ) [33] and one study failed to detect significant incorporation of stable isotope into DHA above background $\left[{ }^{13} \mathrm{C}\right]$ enrichment [25].

Pawlosky et al. [56] have suggested estimates for the efficiency of conversion of individual steps in the desaturation/elongation pathway from kinetic analysis based on the concentrations of individual deuterated fatty acids in plasma from a mixed group of men and women consuming a beef-based diet. The findings of this study were that the efficiency of conversion of $\alpha$ LNA to EPA was $0.2 \%$, of EPA to DPAn-3 65\% and of DPAn-3 to DHA 37\%. This is in general agreement with the studies summarised in Table IV and with the assumption that the first reaction catalysed by $\Delta 6$-desaturase is the rate-limiting step of the pathway. Thus the overall efficiency of conversion from $\alpha \mathrm{LNA}$ is $0.2 \%$ to EPA, $0.13 \%$ to DPA and $0.05 \%$ to DHA.

Several studies have reported the effects of modifications to the background diet on the extent of $\alpha \mathrm{LNA}$ conversion to long chain n-3 PUFA determined by stable isotope tracing. In particular, the effect of increased consumption of LA compared to $\alpha$ LNA has been of interest, as these two fatty acids compete for the rate limiting step of the desaturation/elongation pathway. Likewise the effect of increased consumption of EPA + DHA or DHA alone on this process has been of interest because of the potential for feedback inhibition or inhibition due to competition for $\Delta 6$-desaturase. Emken et al. [54] compared the effect of consuming diets either containing $<0.1 \mathrm{~g}$ DHA per day or supplemented with $6.5 \mathrm{~g} \cdot \mathrm{day}^{-1}$ purified
DHA. There was a $76 \%$ reduction in EPA synthesis and an $88 \%$ reduction in DHA synthesis in the group receiving the DHA supplement. Others have reported a decrease in the conversion efficiency of DPAn-3 to DHA following consumption of a fish-based diet (containing EPA + DHA) compared to a beef-based diet in a mixed group of men and women [57]. However, when the fractional conversion of DPAn-3 to DHA was calculated separately for men and women, the decrease in DHA synthesis as a result of consuming a fish-based diet was only found in the female subjects [58]. Consumption of $1.6 \mathrm{~g}$ per day EPA + DHA for 8 weeks decreased EPA and DPAn-3, but not DHA, synthesis when $\alpha$ LNA conversion was compared before and after the intervention in the same individuals [33]. These studies indicate that increased consumption of long chain n-3 PUFA acts to down-regulate their synthesis from $\alpha$ LNA, although the mechanism by which this occurs is not yet clear. Recently, Hussein et al. [59] have applied kinetic analysis to compare LA and $\alpha$ LNA conversion in subjects consuming either $17 \mathrm{~g}$ per day LA or $\alpha$ LNA. The effect of these diets was to inhibit the conversion of the alternate series of fatty acids, although the apparent synthesis of DHA was consistently low $(<0.01 \%)$ and not influenced by the intakes of these fatty acids. In contrast, one report showed that increased $\alpha$ LNA intake (8 g per day) decreased EPA, DPA and DHA synthesis [30], although others have not found this [33].

Overall, substantial increases in the intakes of individual fatty acids are able to modify the conversion of $\alpha \mathrm{LNA}$, although there are inconsistencies in the magnitude of these effects between reports. The relative effects of LA and $\alpha$ LNA may be explained by competition for $\Delta 6$-desaturase. However, the down regulation of $\alpha$ LNA conversion by DHA or EPA + DHA may have a more complex explanation. Tang et al. [60] have shown recently that the promoter region of $\Delta 6$-desaturase contains the response element for the ligand-activated transcription factor peroxisomal proliferator 
activated receptor- $\alpha$ (PPAR $\alpha)$. This study shows that binding of DHA to PPAR $\alpha$ suppresses transcription of $\Delta 6$-desaturase and so would be expected to down-regulate conversion of $\alpha$ LNA to longer-chain PUFA. Furthermore, the absence of effects of altered background diet on DHA synthesis when conversion of $\alpha$ LNA to EPA and DPAn-3 was decreased supports the suggestion that DHA formation may be regulated independently of other fatty acids in the pathway.

\section{THE EFFECT OF GENDER ON $\alpha$-LINOLENIC ACID METABOLISM}

The majority of investigations of $\alpha$ LNA metabolism in humans have focused on groups of relatively young healthy individuals, either men or mixed groups of men and women. Thus there is relatively little information regarding the effects of gender on this process. Only two reports have specifically studied $\alpha$ LNA conversion in women of reproductive age. Burdge and Wootton [27] showed that conversion of $\alpha$ LNA to EPA and DHA in women aged about 28 years was substantially greater $(2.5$-fold and $>200$-fold, respectively) than in a comparable study of men of similar age [25]. This finding is strongly supported by kinetic analysis which showed that the rate constant coefficient for the conversion of DPAn-3 to DHA was approximately 4-fold greater in women compared to men [58]. In part, this may reflect greater availability of $\alpha$ LNA in women than men due in part to lower partitioning towards $\beta$-oxidation. However, since the rate constant coefficient for the conversion of DPAn-3 to DHA was greater in women than men, it is likely that there is a gender-related difference in the activity of the desaturation/elongation pathway in addition to differences between men and women in the extent of partitioning of $\alpha$ LNA towards $\beta$-oxidation. One possible explanation for the greater synthesis of EPA and DHA from $\alpha$ LNA in women compared to men is the action of oestrogen.
DHA synthesis was almost 3-fold greater in women using an oral contraceptive pill containing $17 \alpha$-ethylnyloestradiol $\left(\mathrm{EE}_{2}\right)$ than in those who were not [27]. The suggestion that oestrogen may increase the activity of the desaturation/elongation pathway is consistent with the finding that oestrogenbased hormone replacement therapy in postmenopausal resulted in greater plasma dihomo- $\gamma$-linolenic and arachidonic acid concentrations than before treatment [61]. Furthermore, DHA concentration in the plasma cholesteryl ester fraction has recently been shown to be greater in women $(0.53 \%$ total fatty acids) compared to men $(0.48 \%$ total fatty acids) consuming diets controlled for energy and $\alpha$ LNA content, although DHA is a minor component of this plasma lipid pool [62]. DHA concentration was also greater in women taking oral contraceptives $(0.58 \%$ total fatty acids) than in those who were not, which is in agreement with the effects of oral contraceptive pill use on $\alpha$ LNA conversion [27]. Interestingly, administration of $\mathrm{EE}_{2}$ to male to female transsexuals increased the concentration of DHA in plasma cholesteryl esters by $42 \%$, while testosterone decreased DHA concentration by $22 \%$ in female to male transsexuals [62]. Together these data strongly support the suggestion that sex hormones regulate the activity of the desaturation/elongation pathway in humans.

One possible biological role for greater capacity for DHA synthesis in women may be in meeting the demands of the fetus and neonate for this fatty acid. The developing human fetus assimilates at least $400 \mathrm{mg}$ DHA per week during the last trimester [63]. Since this estimate reflects only brain, adipose tissue and liver requirements, the overall demands for DHA are likely to be substantially greater. Since desaturase activities in developing human liver appear to be lower than in adults [64-68], the extent to which the fetus and neonate are able satisfy the demands for DHA may be limited. Thus assimilation of DHA by the fetus has to be met primarily by supply of DHA by the mother. In pregnant women, 
plasma PC DHA concentration increases by approximately $33 \%$ between 16 weeks $\left(170 \mu \mathrm{mol} \cdot \mathrm{L}^{-1}\right)$ and 40 weeks $\left(230 \mu \mathrm{mol} \cdot \mathrm{L}^{-1}\right)$ gestation [69]. Studies in rats indicate that this is the result of physiological adaptations to hepatic phospholipid [70] and $\alpha$ LNA [71] metabolism which may serve to facilitate DHA supply to the offspring. When the increase in maternal blood volume during pregnancy is taken into account [72], this adaptation appears to result in an overall doubling of DHA in the circulation. Since circulating oestrogen concentration rises during pregnancy due to synthesis and secretion by the placenta, one possibility is that $\alpha$ LNA conversion may increase during gestation. If so, one implication would be that the $50 \%$ variation among pregnant women in plasma PC DHA concentration at term [69] may reflect differences in $\alpha$ LNA metabolism in addition to any dietary effects, and that this may influence the supply of DHA to the fetus and subsequent developmental and function of fetal tissues.

Consumption of $10.7 \mathrm{~g} \alpha \mathrm{LNA}$ per day by lactating women increased maternal plasma, erythrocyte and breast-milk $\alpha$ LNA concentration [73]. The effect on breast-milk EPA and DPAn-3 concentrations is less clear, as the difference between baseline DPAn-3 concentration $(0.19 \pm 0.05 \%)$ and that after 4 weeks of supplementation $(0.17 \pm 0.02 \%)$ does not support the claim that the DPAn3 content of milk increased over time [73]. Increased consumption of $\alpha$ LNA did not alter breast-milk DHA concentration [73]. This is consistent with the finding that newly synthesised arachidonic acid is a minor component of the arachidonic acid content of breast-milk [74]. This suggests the incorporation of PUFA into milk may be dependent upon mobilisation of stores accumulated before conception and during pregnancy. If so, this emphasises the importance of adequate nutrition of women both before and during pregnancy. Since prolactin suppresses oestrogen activity, the activity of the desaturation/elongation pathway may be down-regulated in lactating compared to non-pregnant and pregnant women, and so these results do not exclude the possibility of increased DHA synthesis during pregnancy.

\section{CONCLUSIONS}

Studies using chronically increased $\alpha$ LNA intake or using a single bolus of isotopically-labelled $\alpha$ LNA yield the same conclusion: that conversion of $\alpha \mathrm{LNA}$ to longer-chain PUFA, particularly DHA, in humans appears to be limited. However, there are important differences between men and women in capacity for synthesis of EPA and DHA from $\alpha$ LNA and this may be affected by physiological state (e.g., pregnancy). If demands for EPA and DHA are modest and primarily serve to support membrane turnover and renewal in adults, then it is possible that in healthy individuals consuming a balanced diet limited capacity for synthesis of EPA and DHA may be sufficient to maintain tissue function. However, in situations where demand for long chain n-3 PUFA, especially DHA, is increased (e.g., during pregnancy and lactation), then synthesis from $\alpha$ LNA may be insufficient to meet the demand, although there may be physiological mechanisms by which $\alpha$ LNA conversion is up-regulated. Clearly more research in this area is required before firmer conclusions can be drawn.

\section{REFERENCES}

[1] Ministry of Agriculture, Fisheries and Food. Food Information Surveillance Sheet 127, Dietary intake of iodine and fatty acids. Ministry of Agriculture, Fisheries and Food, London, 1997.

[2] Hulshof KFAM, van Erp-Baart MA, Anttolainen M, Becker W, Church SM, Couet C, HermannKunz E, Kesteloot H, Leth T, Martins I, Moreiras O, Moschandreas J, Pizzoferrato L, Rimestad AH, Thorgeirsdottir $H$, van Amelsvoort JM, Aro A, Kafatos AG, LanzmannPetithory D, van Poppel G. Intake of fatty acids in Western Europe with emphasis on 
trans fatty acids: the TRANSFAIR Study. Eur J Clin Nutr 1999, 53: 143-157.

[3] Ollis TE, Meyer BJ, Howe PR. Australian food sources and intakes of omega- 6 and omega-3 polyunsaturated fatty acids. Ann Nutr Metab 1999, 43: 346-355.

[4] Kris-Etherton PM, Taylor DS, Yu-Poth S, Huth P, Moriarty K, Fishell V, Hargrove RL, Zhao G, Etherton TD. Polyunsaturated fatty acids in the food chain in the United States. Am J Clin Nutr. 2000, 71 (Suppl): 179S$188 \mathrm{~S}$.

[5] Innis SM, Elias SJ. Intakes of essential n-6 and n-3 polyunsaturated fatty acids among pregnant Canadian women. Am J Clin Nutr 2003 , 77: $473-478$

[6] Astorg P, Arnault N, Czernichow S, Noisette N, Galan P, Hercberg S. Dietary intakes and food sources of n-6 and n-3 PUFA in French adult men and women. Lipids 2004, 39: $527-$ 535.

[7] Sinclair AJ, Attar-Bashi NM, Li D. What is the role of $\alpha$-linolenic acid for mammals? Lipids 2000, 37: 1113-1123.

[8] Alessandri JM, Guesnet P, Vancassel S, Astorg P, Denis I, Langelier B, Aid S, PoumesBallihaut C, Champeil-Potokar G, Lavialle M. Polyunsaturated fatty acids in the central nervous system: evolution of concepts and nutritional implications throughout life. Reprod Nutr Dev 2004, 44: 509-538.

[9] Jeffrey BG, Weisinger HS, Neuringer M, Mitchell DC. The role of docosahexaenoic acid in retinal function. Lipids 2001, 36: 859871.

[10] Mitchell DC, Niu SL, Litman BJ. Enhancement of $\mathrm{G}$ protein-coupled signalling by DHA phospholipids. Lipids 2003, 38: 437-443.

[11] Vinton NE, Heckenlively JR, Laidlaw SA, Martin DA, Foxman SR, Ament ME, Kopple JD. Visual function in patients undergoing parenteral nutrition. Am J Clin Nutr 1990, 52 : 895-902.

[12] Neuringer M, Connor WE, Lin DS, Barstad L, Luck S. Biochemical and functional effects of prenatal and postnatal omega 3 fatty acid deficiency on retina and brain in rhesus monkeys. Proc Natl Acad Sci USA 1986, 83: 40214025.

[13] Connor WE, Neuringer M. The effects of n-3 fatty acid deficiency and repletion upon the fatty acid composition and function of the brain and retina. Prog Clin Biol Res 1988, 282: 275-294.

[14] Unsaturated Fatty Acids: Report of the British Nutrition Foundation's Task Force. Chapman \& Hall, London, 1992.
[15] Briefing Paper: n-3 Fatty Acids and Health. British Nutrition Foundation, London, 1999.

[16] Calder PC. N3 polyunsaturated fatty acids and inflammation: from molecular biology to the clinic. Lipids 2003, 38: 343-352.

[17] Calder PC. N-3 fatty acids and cardiovascular disease: evidence explained and mechanisms explored. Clin Sci (Lond) 2004, 107: 1-11.

[18] De Deckere EA, Korver O, Verschuren PM, Katan MB. Health aspects of fish and n-3 polyunsaturated fatty acids from plant and marine origin. Eur J Clin Nutr 1998, 52: 749-753.

[19] Kris-Etherton PM, HarrisWS, Appel LJ (American Heart Association, Nutrition Committee). Fish consumption, fish oil, omega-3 fatty acids, and cardiovascular disease. Circulation 2002, 106: 2747-2757.

[20] Advice on fish consumption: benefits and risks. SACN/COT Report, TSO, London, 2004.

[21] Emken EA, Adlof RO, Gulley RM. Dietary linoleic acid influences desaturation and acylation of deuterium-labeled linoleic and linolenic acids in young adult males. Biochim Biophys Acta 1994, 1213: 277-288.

[22] Saunders DR, Sillery JK. Absorption of triglyceride by human small intestine: doseresponse relationships. Am J Clin Nutr 1988, 48: 988-991.

[23] Tang AB, Nishimura KY, Phinney SD. Preferential reduction in adipose tissue alpha-linolenic acid (18:3 omega 3 ) during very low calorie dieting despite supplementation with 18:3 omega 3. Lipids 1993, 28: 987-993.

[24] Kaminskas A, Zieden B, Elving B, Kristenson M, Abaravicius A, Bergdahl B, Olsson AG, Kucinskiene $\mathrm{Z}$. Adipose tissue fatty acids in men from two populations with different cardiovascular risk: the LiVicordia study. Scand J Clin Lab Invest 1999, 59: 227-232.

[25] Burdge GC, Jones AE, Wootton SA. Eicosapentaenoic and docosapentaenoic acids are the principal products of $\alpha$-linolenic acid metabolism in young men. Br J Nutr 2002, 88: 355 363.

[26] Evans K, Burdge GC, Wootton SA, Clark ML Frayn KN. Regulation of dietary fatty acid entrapment in subcutaneous adipose tissue and skeletal muscle. Diabetes 2002, 51:26842690.

[27] Burdge GC, Wootton SA. Conversion of $\alpha$ linolenic acid to eicosapentaenoic, docosapentaenoic and docosahexaenoic acids in young women. Br J Nutr 2002, 88: 411-420.

[28] Irving CS, Wong WW, Shulman RJ, Smith EO, Klein PD. $\left[{ }^{13} \mathrm{C}\right]$ Bicarbonate kinetics in 
humans: intra- vs. interindividual variations. Am J Physiol 1983, 245: R190-R202.

[29] DeLany JP, Windhauser MM, Champagne CM, Bray GA. Differential oxidation of individual dietary fatty acids in humans. Am J Clin Nutr 2000, 72: 905-911.

[30] Vermunt SHF, Mensink RP, Simonis AMG, Hornstra G. Effects of dietary $\alpha$-linolenic acid on the conversion and oxidation of $\left[{ }^{13} \mathrm{C}\right]-\alpha-$ linolenic acid. Lipids 2000, 35: 137-142.

[31] Bretillon L, Chardigny JM, Sebedio JL, Noel JP, Scrimgeour CM, Fernie CE, Loreau O, Gachon P, Beaufrere B. Isomerization increases the postprandial oxidation of linoleic acid but not $\alpha$-linolenic acid in men. $\mathrm{J}$ Lipid Res 2001, 42: 995-997.

[32] Clouet P, Niot I, Bezard J. Pathway of alphalinolenic acid through the mitochondrial outer membrane in the rat liver and influence on the rate of oxidation. Comparison with linoleic and oleic acids. Biochem J 1989, 263: 867873.

[33] Burdge GC, Finnegan YE, Minihane AM, Williams CM, Wootton SA. Effect of altered dietary n-3 fatty aid intake upon plasma lipid fatty acid composition, conversion of $\left[{ }^{13} \mathrm{C}\right] \alpha-$ linolenic acid to longer-chain fatty acids and partitioning towards $\beta$-oxidation in older men. Br J Nutr 2003, 90: 311-321.

[34] Sheaff-Greiner RC, Zhang Q, Goodman KJ, Giussani DA, Nathanielsz PW, Brenna JT. Linoleate, $\alpha$-linolenate, and docosahexaenoate recycling into saturated and monounsaturated fatty acids is a major pathway in pregnant or lactating adults and fetal or infant rhesus monkeys. J Lipid Res 1996, 37: 2675-2686.

[35] Cunnane SC, Williams SC, Bell JD, Brookes S, Craig K, Iles RA, Crawford MA. Utilization of uniformly labeled ${ }^{13} \mathrm{C}$-polyunsaturated fatty acids in the synthesis of long-chain fatty acids and cholesterol accumulating in the neonatal rat brain. J Neurochem 1994, 62: 2429-2436.

[36] Cunnane SC, Ryan MA, Nadeau CR, Bazinet RP, Musa-Veloso K, McCloy U. Why is carbon from some polyunsaturates extensively recycled in lipid synthesis? Lipids 2003, 38: $477-484$

[37] Burdge GC, Wootton SA. Conversion of $\alpha-$ linolenic acid to palmitic, palmitoleic, stearic and oleic acids in men and women. Prostaglandins Leukot Essent Fat Acids 2003, 69: 283-290.

[38] Sprecher H. The roles of anabolic and catabolic reactions in the synthesis and recycling of polyunsaturated fatty acids. Prostaglandins. Leukot Essent Fat Acids 2002, 67: 79-83.
[39] Infante JP, Huszagh VA. Analysis of the putative role of 24-carbon polyunsaturated fatty acids in the biosynthesis of docosapentaenoic (22:5nn-6) and docosahexaenoic (22:6n-3) acids. FEBS Lett 1998, 43: 1-6.

[40] Li Z, Kaplan ML, Hachey DL. Hepatic microsomal and peroxisomal docosahexaenoate biosynthesis during piglet development. Lipids 2000, 35: 1325-1333.

[41] Harmon SD, Kaduce TL, Manuel TD, Spector AA. Effect of $\Delta 6$-desaturase inhibitor SC26196 on PUFA metabolism in human cells. Lipids 38: 469-476.

[42] De Antueno RJ, Knickle LC, Smith H, Elliot ML, Allen SJ, Nwaka S, Winther MD. Activity of human $\Delta 5$ and $\Delta 6$ desaturases on multiple n-3 and n-6 polyunsaturated fatty acids. FEBS Lett 2001, 509: 77-80.

[43] D'andrea S, Guillou H, Jan S, Catheline D, Thibault JN, Bouriel M, Rioux V, Legrand P. The same rat $\Delta 6$-desaturase not only acts on 18 - but also on 24-carbon fatty acids in verylong-chain polyunsaturated fatty acid biosynthesis. Biochem J 2002, 364, 49-55.

[44] Sanders TA, Younger KM. The effect of dietary supplements of omega 3 polyunsaturated fatty acids on the fatty acid composition of platelets and plasma choline phosphoglycerides. Br J Nutr 1981, 45: 613-616.

[45] Mantzioris E, James MJ, Gibson RA, Cleland LG. Dietary substitution with an alpha-linolenic acid-rich vegetable oil increases eicosapentaenoic acid concentrations in tissues. Am J Clin Nutr 1994, 59: 1304-1309.

[46] Cunnane SC, Hamadeh MJ, Liede AC, Thompson LU, Wolever TM, Jenkins DJ. Nutritional attributes of traditional flaxseed in healthy young adults. Am. J Clin Nutr 1995, 61: 62-68.

[47] Li D, Sinclair A, Wilson A, Nakkote S, Kelly F, Abedin L, Mann N, Turner A. Effect of dietary alpha-linolenic acid on thrombotic risk factors in vegetarian men. Am J Clin Nutr 1999, 69: 872-882.

[48] Wallace FA, Miles EA, Calder PC. Comparison of the effects of linseed oil and different doses of fish oil on mononuclear cell function in healthy human subjects. Br J Nutr 2003, 89: 679-689.

[49] Finnegan YE, Minihane AM, Leigh-Firbank EC, Kew S, Meijer GW, Muggli R, Calder PC, Williams CM. Plant- and marine-derived n-3 polyunsaturated fatty acids have differential effects on fasting and postprandial blood lipid concentrations and on the susceptibility of LDL to oxidative modification in moderately hyperlipidemic subjects. Am J Clin Nutr 2003, 77: 783-795. 
[50] James MJ, Ursin VM, Cleland LG. Metabolism of stearidonic acid in human subjects: comparison with the metabolism of other $n-3$ fatty acids. Am J Clin Nutr 2003, 77: 11401145.

[51] Chan JK, McDonald BE, Gerrard JM, Bruce VM, Weaver BJ, Holub BJ. Effect of dietary alpha-linolenic acid and its ratio to linoleic acid on platelet and plasma fatty acids and thrombogenesis. Lipids 1993, 28: 811-817.

[52] Emken EA. Stable isotope approaches, applications and issues related to polyunsaturated fatty acid metabolism studies. Lipids 2001, 36: 965-973.

[53] Healy DA, Wallace FA, Miles EA, Calder PC, Newsholm P. Effect of low-to-moderate amounts of dietary fish oil on neutrophil lipid composition and function. Lipids 2000, 35: 763-768.

[54] Emken EA, Adlof RO, Duval SM, Nelson GJ. Effect of dietary docosahexaenoic acid on desaturation and uptake in vivo of isotopelabeled oleic, linoleic and linolenic acids by male subjects. Lipids 1999, 34: 785-798.

[55] Salem N, Powlosky R, Wegher B, Hibbeln J. In vivo conversion of linoleic acid to arachidonic acid in human adults. Prostaglandins Leukot Essent Fat Acids 1999, 60: 407-410.

[56] Pawlosky RJ, Hibbeln JR, Novotny JA, Salem $\mathrm{N}$. Physiological compartmental analysis of $\alpha$-linolenic acid metabolism in adult humans. J Lipid Res 2001, 42: 1257-1265.

[57] Pawlosky RJ, Hibbeln JR, Lin Y, Goodson S, Riggs P, Sebring N, Brown GL, Salem N. Effects of beef- and fish-based diets on the kinetics of n-3 fatty acid metabolism in human subjects. Am J Clin Nutr 2003, 77: 565-572.

[58] Pawlosky R, Hibbeln J, Lin Y, Salem N. N-3 fatty acid metabolism in women. $\mathrm{Br} \mathrm{J}$ Nutr 2003, 90: 993-994.

[59] Hussein N, Ah-Sing E, Wilkinson P, Leach C, Griffin BA, Millward DJ. Relative rates of long chain conversion of ${ }^{13} \mathrm{C}$ linoleic and $\alpha$ linolenic acid in response to marked changes in their dietary intake in male adults. J Lipid Res 2005, 46: 269-280.

[60] Tang C, Cho HP, Nakamura MT, Clarke SD. Regulation of human $\Delta-6$ desaturase gene transcription: identification of a functional direct repeat-1 element. J Lipid Res 2003, 44: 686-695.

[61] Ottosson UB, Lagrelius A, Rosing U, von Schoultz B. Relative fatty acids composition of lecithin during postmenopausal replacement therapy - a comparison between ethinyl estradiol and estradiol valerate. Gynecol Obstet Invest 1984, 18: 296-302.
[62] Giltay EJ, Gooren LJ, Toorians AW, Katan MB, Zock PL. Docosahexaenoic acid concentrations are higher in women than in men because of estrogenic effects. Am J Clin Nutr 2004, 80: 1167-1174.

[63] Lauritzen L, Hansen HS, Jorgensen MH, Michaelsen KF. The essentiality of long chain $\mathrm{n}-3$ fatty acids in relation to development and function of the brain and retina. Prog Lipid Res 2001, 40: 1-94.

[64] De Gomez Dumm IN, Brenner RR. Oxidative desaturation of alpha-linoleic, linoleic, and stearic acids by human liver microsomes. Lipids 1975, 10: 315-317.

[65] Poisson J-P, Dupuy R-P, Sarda P, Descomps B, Narce M, Rieu D, Crastes de Paulet A. Evidence that liver microsomes of human neonates desaturate essential fatty acids. Biochim Biophys Acta 1993, 1167: 109-113.

[66] Salem N, Wegher B, Mena P, Uauy R. Arachidonic and docosahexaenoic acids are biosynthesized from their 18-carbon precursors in human infants. Proc Natl Acad Sci USA 1996, 93: 49-54.

[67] Carnielli VP, Wattimena DJ, Luijendijk IH, Boerlage A, Degenhart HJ, Sauer PJ. The very-low-birth-weight premature infant is capable of synthesizing arachidonic and docosahexaenoic acid from linolenic and linolenic acid. Pediatr Res 1996, 40: 169-174.

[68] Sauerwald TU, Hachey DL, Jensen CL, Chen $\mathrm{H}$, Anderson RE, Heird WC. Intermediates in endogenous synthesis of $\mathrm{C} 22: 6 \omega 3$ and C20: $4 \omega 6$ by term and preterm infants. Pediatr Res 1997, 41: 183-187.

[69] Postle AD, Al MDM, Burdge GC, Hornstra G. The composition of individual molecular species of plasma phosphatidylcholine in human pregnancy. Early Human Dev 1995, 43: 47-58.

[70] Burdge GC, Hunt AN, Postle AD. Mechanisms of hepatic phosphatidylcholine synthesis in adult rat: effects of pregnancy. Biochem J 1994, 303: 941-947.

[71] Larque E, Garcia-Ruiz PA, Perez-Llamas F, Zamora S, Gil A. Dietary trans fatty acids alter the compositions of microsomes and mitochondria and the activities of microsome $\Delta 6$ fatty Acid desaturase and glucose-6-phosphatase in livers of pregnant rats. J Nutr 2003, 133: 2526-2531.

[72] Gregersen MI, Rawson RA. Blood Volume. Physiol Rev 1959, 39: 307-342.

[73] Francois CA, Connor SL, Bolewicz LC, Connor WE. Supplementing lactating women with flaxseed oil does not increase docosahexaenoic acid in their milk. Am J Clin Nutr 2003, 77: 226-233. 
[74] Del Prado M, Villalpando S, Elizondo A, Rodriguez M, Demmelmair H, Koletzko B. Contribution of dietary and newly formed arachidonic acid to human milk lipids in women eating a low-fat diet. Am J Clin Nutr 2001, 74 : 242-247.

[75] Kelley DS, Nelson GJ, Love JE, Branch LB, Taylor PC, Schmidt PC, Mackey BE, Iacono JM. Dietary alpha-linolenic acid alters tissue fatty acid composition, but not blood lipids, lipoproteins or coagulation status in humans. Lipids 1993, 28: 533-537.

[76] Bemelmans WJ, Broer J, Feskens EJ, Smit AJ, Muskiet FA, Lefrandt JD, Bom VJ, May JF, Meyboom-de Jong B. Effect of an increased intake of alpha-linolenic acid and group nutritional education on cardiovascular risk factors: the Mediterranean Alpha-linolenic Enriched Groningen Dietary Intervention (MARGARIN) study. Am J Clin Nutr 2002, 75: 221227.

[77] Sanders TA, Roshanai F. The influence of different types of omega 3 polyunsaturated fatty acids on blood lipids and platelet function in healthy volunteers. Clin Sci (Lond) 1983, 64: 91-99.

[78] Weaver BJ, Corner EJ, Bruce VM, McDonald BE, Holub BJ. Dietary canola oil: effect on the accumulation of eicosapentaenoic acid in the alkenylacyl fraction of human platelet eth- anolamine phosphoglyceride. Am J Clin Nutr 1990, 51: 594-598.

[79] Kwon JS, Snook JT, Wardlaw GM, Hwang DH. Effects of diets high in saturated fatty acids, canola oil, or safflower oil on platelet function, thromboxane B2 formation, and fatty acid composition of platelet phospholipids. Am J Clin Nutr 1991, 54: 351-358.

[80] Mutanen M, Freese R, Valsta LM, Ahola I, Ahlstrom A. Rapeseed oil and sunflower oil diets enhance platelet in vitro aggregation and thromboxane production in healthy men when compared with milk fat or habitual diets. Thromb Haemost 1992, 67: 352-356.

[81] Allman MA, Pena MM, Pang D. Supplementation with flaxseed oil versus sunflowerseed oil in healthy young men consuming a low fat diet: effects on platelet composition and function. Eur J Clin Nutr 1995, 49: 169-178.

[82] Caughey GE, Mantzioris E, Gibson RA, Cleland LG, James MJ. The effect on human tumor necrosis factor alpha and interleukin 1 beta production of diets enriched in $\mathrm{n}-3$ fatty acids from vegetable oil or fish oil. Am J Clin Nutr 1996, 63: 1116-1122.

[83] Kew S, Banerjee T, Minihane AM, Finnegan YE, Muggli R, Albers R, Williams CM, Calder PC. Lack of effect of foods enriched with plant- or marine-derived n-3 fatty acids on human immune function. Am J Clin Nutr 2003, 77: 1287-1295. 